comprehensive account of the present state of knowledge. In the North Atlantic Ocean, as in the other main oceans, an anticyclonic wind system produces a current system in the same sense, and the main problem is that if the wind system, which is a broad widespread phenomenon, drives the ocean currents, why is the current system so asymmetrical with its strongest currents squeezed into a narrow strip on the western side of the Ocean ?

The simplest explanation involves consideration of the forces due to the Earth's rotation, and the fact that a steady state eannot be reached until the angular momentum added to the water by the wind is balanced by the changes in vorticity which occur as the water moves north or south into parts of the Earth that have different angular rotation. The wind introduces a clockwise spin, the movement of water northwards from an area of the Earth with less anticlockwise spin to one of more anticlockwise spin increases its own clockwise momentum relative to the Earth. To balance such an effect, the simplest theory suggests that there are frictional forces generated in a thin poleward-flowing current in the western marginal region. An alternative theory due to Charney replaces the 'frictional' layer by an inertial boundary layer.

Dr. Stommel gives detailed descriptions of the mathematical models expressing these theories, and shows that the current is really a flow along the boundary between masses of cold and warm water, so that it might be better to study the origin and nature of these two water masses and to treat the current as a secondary feature. This leads him to a tentative new theory of the circulation likely to be caused by differences of temperature and salinity between one part of the Ocean and another, and to a stimulating and critical review of the whole state of our knowledge of the physical processes. He does not belittle the survey type of oceanography, nor theoretical speculation, but makes a strong plea that more attention be given to the difficult middle ground, the testing of hypotheses. This sets the pattern of his book; he gives a fine historical introduction, an account of the methods used to study the current, a surnmary of what we know about the properties of the water, velocities and seasonal changes, and does everything possible to test the various ideas that have been put forward. To-day a great deal of effort of the kind he has long advocated is being devoted to the study of the Gulf Stream, and although it must add to what he has written it will not reduce the value of the book.

G. E. R. DEACON

\section{THE TWO R's OF PLANT BREEDING} Abstract Bibliography of Fruit Breeding and Genetics to 1955

Rubus and Ribes-a Survey. By Dr. R. L. Knight and Elizabeth Keep. (Technical Communication No. 25 of the Commonwealth Bureau of Horticulture and Plantation Crops.) Pp. iii +254 . (Farnham Royal : Commonwealth Agricultural Bureaux, 1958.) 45s. ; 6.80 dollars.

$\mathrm{D}$ R. R. L. KNIGH'l, in charge of raspberry and currant breeding at East Malling since 1954 and Miss E. Keep have built up a useful abstracted bibliography on Ribes and Rubus. For the spocialist such a work neods not only to be complete, but also the abstracts, particularly of papers in foreign languages and in obscure journals, must be sufficiently detailed to be of value. The authors have only partially succeeded in this last respect. The bibliography is incomplete, and several recent important papers by British authors on the cytology and genetics of British forms of Rubus are unfortunately listed by title only. Some of the individual abstracts are good, for example, the salient features of the 76-page paper of Fassett on mass collections are condensed into ten lines. Some other abstracts appear to be condensations of earlier abstracts, and one wonders if these have been verified: for example, work by Dowrick is wrongly attributed to LaCour. Bibliographical errors are few : Zinno should read Jinno.

One disadvantage of a bibliography is that a newcomer is not readily able to assess the rolative merits of the individual papers, and here the compilers have not helped. Although some papers, such as Spinks's on black currant breeding at Long Ashton, are fully abstracted, the length of an abstract provides little indication of a paper's scientific merits. This book would, therefore, have benefited from sieving. Some of the now worthless earlier papers could have been omitted, and the space used to provide the authors' comments on the more important ones.

A most unfortunate decision has been to mix the references of Ribes with Rubus. Two separate bibliographies with their own indices would have been an advantage, especially when surveying previous work on each genus, and in using the subject index.

Two appendixes are provided. That of a gene list for Rubus concerns only raspberry, but several genes are known in blackberry ; it is perhaps unfortunate that the symbol $A$ is given to Amphorophora resistance, as this had already been assigned to autumn flowering (not listed). Appendix II gives two linkage groups, of especial interest for until now it had seemed that all the tested genes in Rubus lie on one chromosome, and the remaining six chromosomes were possibly inort. No gene list is given for Ribes, although data are available in the omitted "Genetics of Garden Plants" (Crane and Lawrence). No list of chromosome numbers is provided, which would have been useful as there is no reference to Darlington and Wylie's "Chromosome Atlas".

A graph, calculated from the bibliography, clearly shows that breeders have been, and will be, more interested in raspberries, blackberries and kindred fruits, than in gooseberries and currants. Indeod, research with Rubus now considerably outstrips that for Ribes. This is partly because Rubus affords more genetically versatile experimental material, and partly from lack of interest in Ribes in North America, where Ribes cultivation is banned. Yet the considerable demand for black currant juice abroad provides the basis for the present policy at Mylnefield to breed high-yielding, uniform, early ripening varieties, to increase the acreage in the soft-fruit areas of the East of Scotland.

This expensive bibliography was already three years out of date when it went to press. Hence important new works like Watson's monograph on British forms of Rubus are not included. The publishers and authors might consider, therefore, issuing to purchasers a free mimeographed supploment bringing the list up to date. Generally this compila. tion will save time, but it is hoped that those who use it will not by-pass the originals, unless we may conclude that nowadays only summaries really need be published.
G. HASKELI 